\title{
НАУЧНОЕ ОБОСНОВАНИЕ ПРИМЕНЕНИЯ РЕЗУЛЬТАТОВ АНТРОПОМЕТРИЧЕСКИХ ИССЛЕДОВАНИЙ И БИОИМПЕДАНСНОГО АНАЛИЗА В КАЧЕСТВЕ КРИТЕРИЕВ ОЦЕНКИ ЭФФЕКТИВНОСТИ ОЗДОРОВЛЕНИЯ ДЕТЕЙ В ЛЕТНИХ ЛАГЕРЯХ
}

М. Ю. Гаврюшин, О. В. Сазонова, Д. О. Горбачев, Л. М. Бородина, О. В. Фролова, Д. С. Тупикова

Самарский государственный медицинский университет, Самара, Россия

В современных условиях жизни высока доля детей с избыточной массой тела и ожирением. Очевидна необходимость оздоровления детей, способствующего коррекции пищевого статуса. На выполнение этой задачи направлена работа детских организаций отдыха и оздоровления, в том числе летних лагерей. Необходимы анализ различных методов оценки изменений пищевого статуса детей в течение лагерной смены и научное обоснование возможности применения результатов биоимпедансного анализа состава тела (БИА) и антропометрических измерений в качестве критериев оценки эффективности оздоровления детей в лагерях. Обследованы 125 мальчиков и 221 девочка в возрасте 8-15 лет, отдыхающие в трех детских лагерях. Исследования проводили в 2 этапа: на 1-й, 2-й дни заезда и за 2 дня до окончания лагерной смены. В каждой организации выявлены дети, у которых за период лагерной смены отмечена как положительная, так и отрицательная тенденция изменения массы тела. Общая тенденция к изменению массы тела среди детей в лагерях № 1 и № 2 была статистически незначима ( $p=0,415$ и $p=0,585)$, а в лагере № 3 отмечена достоверная тенденция к изменению массы тела отдыхающих ( $p=0,025)$. По данным БИА, повышение массы тела в течение лагерной смены не более чем в 44,34\% случаев сопровождалось должным повышением скелетно-мышечной составляющей, а снижение массы тела включало потерю как жировой, так и скелетно-мышечной составляющих. БИА не только дополняет результаты антропометрических исследований, но и позволяет сделать предположение о фактическом питании и уровне двигательной активности детей. Соответственно, применение антропометрических исследований в совокупности с данными БИА может служить в качестве информативного методического подхода к оценке эффективности оздоровления детей в летних лагерях.

Ключевые слова: гигиена детей и подростков, физическое развитие, антропометрия, биоимпедансный анализ, пищевой статус, рацион питания

Информация о вкладе авторов: М. Ю. Гаврюшин — планирование исследования, сбор данных, анализ данных, интерпретация результатов; О. В. Сазонова планирование исследования, интерпретация результатов; Д. О. Горбачев - анализ литературы, подготовка черновика рукописи; Л. М. Бородина - анализ данных, интерпретация результатов; О. В. Фролова - редактирование статьи, анализ литературы; Д. С. Тупикова - подготовка черновика рукописи.

Соблюдение этических стандартов: исследование одобрено экспертной комиссией ФГБОУ ВО СамГМУ Минздрава России (протокол № 8 от 13 сентября 2018 г.). Все участники исследования (или их законные представители) подписали информированное согласие на участие в исследовании.

Для корреспонденции: Михаил Юрьевич Гаврюшин ул. Чапаевская, д. 87, г. Самара, 443099; m.уu.samara@mail.ru

Статья получена: 10.12.2018 Статья принята к печати: 29.03.2018 Опубликована онлайн: 12.04.2019

DOI: 10.24075 /vrgmu.2019.024

\section{A RATIONALE FOR THE USE OF ANTHROPOMETRIC MEASUREMENTS AND BIOELECTRICAL IMPEDANCE ANALYSIS AS EFFICACY CRITERIA FOR SUMMER CAMP HEALTHCARE}

Gavryushin MYu凶, Sazonova OV, Gorbachev DO, Borodina LM, Frolova OV, Tupikova DS

Samara State Medical University, Samara, Russia

The proportion of obese and overweight children is alarmingly high. This dictates the need for promoting healthy lifestyle and eating habits in children. Summer camps provide a wide range of activities to improve children's health. However, methods used to assess children's nutritional status during a camp session need to be analyzed in depth, and a rationale should be provided for the use of bioelectrical impedance analysis (BIA) and anthropometric measurements as efficacy criteria for summer camp healthcare. We examined 125 boys and 221 girls aged 8-15 years spending their summer holidays at 3 different camps. Measurements were taken twice: on days 1 and 2 upon arrival to a camp and 2 days before leaving for home. In each camp, both positive and negative health weight dynamics were observed. The overall weight dynamics in children from camps 1 and 2 were statistically insignificant $(p=0.415$ and $p=0.585)$, in contrast to camp 3 where those changes were significant $(p=0.025)$. BIA revealed that less than $44.34 \%$ of children had gained skeletal muscle mass during their stay at the camp, whereas weight loss was associated with both decreased fat and skeletal muscle masses. BIA confirms the results of anthropometric measurements and also provides information about the diet offered to children and their level of physical activity. Therefore, the use of anthropometric measurements and BIA could be an informative method for assessing the efficacy of healthcare in summer camps.

Keywords: hygiene of children and adolescents, physical development, anthropometry, bioimpedance analysis, nutritional status, diet

Author contribution: Gavryushin MYu — study design, data acquisition and analysis, interpretation of the results; Sazonova OV — study design, interpretation of the results; Gorbachev DO - literature analysis, manuscript draft; Borodina LM — data analysis, interpretation of the results; Frolova OV — manuscript revision, literature analysis; Tupikova DS — manuscript draft.

Compliance with ethical standards: this study was approved by the Ethics Committee of Samara State Medical University (Protocol No. 8 dated September 13 , 2018). Informed consent was obtained from all the participants or their legal representatives.

Correspondence should be addressed: Mikhail Yu. Gavryushin

Chapaevskaya 87, Samara, 443099; m.yu.samara@mail.ru

Received: 10.12.2018 Accepted: 29.03.2018 Published online: 12.04.2019

DOI: $10.24075 /$ brsmu.2019.024

Важнейшим критерием комплексной оценки состояния здоровья, наряду с другими показателями, используемыми для определения группы здоровья детей, является физическое развитие [1, 2]. В современных условиях жизни дисгармоничное физическое развитие отмечают более чем у $25 \%$ детей и подростков школьного возраста [3-5], выявлен высокий удельный вес детей с избыточной массой тела и ожирением [1, 3, 6-9]. В значительной мере причиной тому служат изменения условий и образа жизни, в том числе рациона питания, который обеспечивает нормальный рост и развитие, способствует профилактике заболеваний и создает оптимальные условия для адаптации человека к воздействию окружающей среды $[10,11]$ 
Нерациональная структура продуктового набора и характер питания в критические периоды онтогенеза воздействуют на рост и развитие ребенка, а также способствуют возникновению множества заболеваний [12-14]. Так, в Самарской области впервые выявленная заболеваемость ожирением детского населения на протяжении многих лет остается на высоком уровне и в 2016 г. составила 54,1 случай на 10 тыс. детей, что превышает среднероссийский уровень, равный 36,7 [15].

Очевидна необходимость оздоровления детей и коррекции пищевого статуса. Благоприятным временем для выполнения данной задачи представляется летний период года, когда важнейшую роль играют детские лагеря, в которых ребенок должен быть обеспечен комплексом оздоровительных мероприятий и оптимальными условиями пребывания. Рацион питания служит важнейшим фактором, определяющим динамику состояния здоровья, процессы роста и развития, и изменение статуса питания, что в совокупности характеризует эффективность оздоровления [16].

Современные достижения научного сообщества к настоящему времени позволили разработать критерии оценки эффективности оздоровления детей в лагерях. В методических рекомендациях МР 2.4.4.0127-18 «Методика оценки эффективности оздоровления в стационарных организациях отдыха и оздоровления детей» (введены взамен MP 2.4.4.0011-10) изложена балльная система оценки эффективности оздоровления детей, основанная на определении динамики изменений роста, массы тела, мышечной силы и функции внешнего дыхания в течение лагерной смены [17]. Профильной комиссией Министерства здравоохранения России по гигиене детей и подростков утвержден федеральный протокол ФП РОШУМЗ-15-2014 «Комплексная оценка эффективности оздоровления в загородных стационарных организациях отдыха и оздоровления детей» (протокол № 4 от 6 мая 2014 г.). Протокол содержит методику оценки эффективности оздоровления детей на основе динамики показателей физического развития (длины и массы тела), функциональных возможностей сердечнососудистой и дыхательной систем организма, физической подготовленности и показателей заболеваемости ребенка за период смены. Помимо динамики изменений указанных показателей, авторы научных исследований рекомендуют использовать в качестве критериев эффективности оздоровления изменения функциональной пробы с дозированной физической нагрузкой [18], величину двигательной активности [19] и изменения умственной работоспособности [20].

На наш взгляд, оценка эффективности оздоровления детей должна учитывать изменения пищевого статуса в течение лагерной смены. Достоверная оценка, анализ динамики изменений и своевременное выявление нарушений пищевого статуса могут способствовать снижению числа алиментарнозависимых заболеваний среди населения [21].

Предложенные ранее методики оценки эффективности оздоровления детей включают анализ динамики изменений антропометрических признаков у отдыхающих с различными группами физического развития. В последнее время для оценки пищевого статуса, помимо общепринятого расчетного антропометрического метода, используют различные аппаратные диагностические методы [21, 22]. Одним из них является биоимпедансный анализ состава тела (БИА). Возможность применения БИА для оценки эффективности оздоровления детей в части коррекции пищевого статуса требует изучения.
Цель работы заключалась в научном обосновании возможности применения результатов биоимпедансного исследования состава тела в совокупности с данными антропометрических измерений как критериев оценки эффективности оздоровления детей в летних лагерях.

\section{ПАЦИЕНТЫ И МЕТОДЫ}

Объектом исследования были дети и подростки, отдыхающие в трех летних организациях отдыха и оздоровления детей Самарской области. Выбор организаций отдыха осуществляли из числа тех, руководители которых одобрили участие детей в исследовании. Участие в исследовании нескольких организаций было обусловлено возможностью получения различных результатов динамики изменения антропометрических и биоимпедансометрических показателей. Каждая изученная организация была обеспечена необходимыми условиями для создания должного уровня двигательной активности (игровые и спортивные площадки, физкультурно-оздоровительные комплексы) и полноценного питания (базовые столовые) отдыхающих детей. Среди участвующих в исследовании организаций не было лагерей со спортивной направленностью, режим дня был стандартным для организаций подобного типа. В группу наблюдения вошли 346 детей (125 мальчиков и 221 девочка) в возрасте 8-15 лет. Критерии включения детей в исследование: постоянное проживание на территории Самарской области; соответствие состояния здоровья I или II группе здоровья по данным медицинской документации.

Критерии исключения: наличие хронических заболеваний; прием лекарственных препаратов; наличие выраженных отеков конечностей; постоянное проживание за пределами Самарской области; отказ родителей (или законных представителей) подписать согласие на участие в исследовании

Все исследования проводили в два этапа: первый этап - на 1-2-й дни заезда лагерной смены; второй этап - за 2 дня до окончания лагерной смены. Продолжительность лагерной смены в организациях отдыха и оздоровления составляла 21 день. Измерение антропометрических показателей осуществляли по стандартной унисицированной методике [23]: рост измеряли с помощью штангового антропометра (Кафа; Россия) с точностью до 0,5 см, массу тела - на электронных медицинских весах ВЭМ-150-«Масса-К» (Масса-К; Россия) с точностью до 60 г. Оценку уровня физического развития детей проводили по региональным модифицированным шкалам регрессии для Самарского региона [24]. БИА состава тела проводили с помощью анализатора внутренних сред организма АВС-01 «Медасс» (Медасс; Россия) на частоте зондирующего тока 50 кГц по стандартной тетраполярной схеме с наложением электродов в область лучезапястного и голеностопного суставов при нахождении испытуемого в положении лежа на спине. В процессе проведения процедуры обращали внимание на угол между плечом правой руки и вертикальной осью туловища, который согласно методике, должен составлять 45; предплечье правой руки обследуемых располагалось параллельно вертикальной оси туловища, ноги - на ширине плеч. БИА проводили утром натощак или через 2,5-3 ч после приема пищи. Обследованию не предшествовали интенсивные физические нагрузки, физиотерапевтические процедуры. Методом БИА оценивали жировую массу (ЖМ), скелетно-мышечную 
массу (СММ) и уровень удельного обмена (УО) [25, 26]. Сбор и хранение первичных данных выполняли в среде «Microsoft Excel 2010» (Microsoft; США). Статистическую обработку полученных материалов проводили с использованием пакета программ Statistica (StatSoft Inc.; США, версия 13.1). Статистический анализ общей тенденции к изменению массы тела в течение лагерной смены проводили с применением парного критерия Уилкоксона. Изменение доли детей с нормальным физическим развитием (НФР), десицитом массы тела (ДМТ) и избытком массы тела (ИМТ) оценивали с помощью критерия хи-квадрат МакНемара. Сравнение долей в независимых группах (из разных лагерей) выполняли с помощью критерия хи-квадрат Пирсона. Различия сравниваемых результатов ( $\mathrm{M} \pm m$, где М - выборочное среднее арифметическое, а $m$ - ошибка среднего арифметического) считались статистически значимыми при достигнутом уровне значимости $p<0,05$.

\section{РЕЗУЛЬТАТЫ ИССЛЕДОВАНИЯ}

Проведен анализ общей тенденции изменений уровня физического развития среди отдыхающих детей в каждой организации отдыха и оздоровления. Результаты изменений в лагере № 1 представлены в табл. 1.

В течение смены в лагере № 1 не изменился уровень физического развития у 62 детей с НФР (47,7\%), у
19 отдыхающих с ДМТ (14,6\%) и 31 ребенка с ИМТ (23,8\%). Положительную тенденцию перехода в группу с НФР в течение лагерной смены наблюдали среди 8 детей с ДМТ (6,2\%) и 5 отдыхающих с ИМТ (3,8\%). Отрицательная динамика отмечена у 4 детей (3,1\%), перешедших из группы с НФР в начале смены в группу с ДМТ к концу смены, а также у 1 ребенка (0,8\%), который в начале смены имел нормальное физическое развитие, а к концу смены у него отмечен избыточный статус питания и, соответственно, он перешел в группу детей с ИМТ. Однако общая тенденция к изменению массы тела у детей в лагере статистически незначима $(p=0,415)$.

При анализе тенденций изменения доли детей с НФР, ИМТ и ДМТ в течение смены лагеря № 1 по каждой группе в отдельности статистически значимых результатов не выявлено (табл. 2).

Аналогичный анализ изменений уровня фризического развития проведен в лагере № 2. Выявлено, что в течение смены не изменился уровень физического развития у 56 детей с НФР (48,7\%), у 16 отдыхающих с ДМТ (13,9\%) и 31 ребенка с ИМТ (27\%) (табл. 3).

Положительная тенденция перехода в группу с НФР в течение лагерной смены выявлена у 5 детей с ДМТ (4,3\%) и 2 отдыхающих с ИМТ (1,7\%). Отрицательная динамика, а именно переход в группу с ДМТ, отмечена у 3 детей $(2,6 \%)$, а в группу с ИМТ - у 2 (1,7\%) (табл. 4). Общая тенденция

Таблица 1. Анализ общей тенденции изменений уровня физического развития в лагерях

\begin{tabular}{|c|c|c|c|c|c|}
\hline \multirow{2}{*}{\multicolumn{2}{|c|}{ Начало смены }} & \multicolumn{3}{|c|}{ Конец смены } & \multirow{3}{*}{$\begin{array}{c}\text { Итого } \\
67\end{array}$} \\
\hline & & \multirow{2}{*}{$\begin{array}{c}\mathrm{HФP} \\
62\end{array}$} & \multirow{2}{*}{$\begin{array}{c}\text { ДМТ } \\
4 \\
\end{array}$} & \multirow{2}{*}{$\frac{\text { ИМТ }}{1}$} & \\
\hline HAD & Абс. & & & & \\
\hline 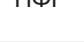 & $\%$ & 47,7 & 3,1 & 0,8 & 51,5 \\
\hline \multirow{2}{*}{ ДМТ } & Абс. & 8 & 19 & 0 & 27 \\
\hline & $\%$ & 6,2 & 14,6 & 0 & 20,8 \\
\hline \multirow{2}{*}{ ИМт } & Абс. & 5 & 0 & 31 & 36 \\
\hline & $\%$ & 3,8 & 0 & 23,8 & 27,7 \\
\hline \multirow{2}{*}{ Итого } & Абс. & 75 & 23 & 32 & 130 \\
\hline & $\%$ & 57,7 & 17,7 & 24,6 & 100 \\
\hline
\end{tabular}

Таблица 2. Анализ тенденций изменений доли детей с НФР, ИМТ и ДМТ в течение смены лагеря № 1

\begin{tabular}{|c|c|c|c|c|c|c|}
\hline \multirow{2}{*}{ Показатель изменений } & \multicolumn{2}{|c|}{ НФР } & \multicolumn{2}{|c|}{ ДМТ } & \multicolumn{2}{|c|}{ ИМТ } \\
\hline & $n$ & $\%$ & $n$ & $\%$ & $n$ & $\%$ \\
\hline Увеличилось число детей & 13 & 10 & 4 & 3,1 & 1 & 0,8 \\
\hline Уменьшилось число детей & 5 & 3,8 & 8 & 6,2 & 5 & 3,8 \\
\hline Без изменений & 112 & 86,2 & 118 & 90,8 & 124 & 95,4 \\
\hline Итого & 130 & 100 & 130 & 100 & 130 & 100 \\
\hline Статистическая значимость, $p$ & \multicolumn{2}{|c|}{0,096} & \multicolumn{2}{|c|}{0,388} & \multicolumn{2}{|c|}{0,219} \\
\hline
\end{tabular}

Таблица 3. Анализ изменений уровня физического развития среди детей в лагере № 2

\begin{tabular}{|c|c|c|c|c|c|}
\hline \multirow{2}{*}{\multicolumn{2}{|c|}{ Начало смены }} & \multicolumn{3}{|c|}{ Конец смены } & \multirow{3}{*}{$\begin{array}{r}\text { Итого } \\
61\end{array}$} \\
\hline & & \multirow{2}{*}{$\frac{\mathrm{H} \Phi \mathrm{P}}{56}$} & \multirow{2}{*}{$\begin{array}{c}\text { ДМТ } \\
3\end{array}$} & \multirow{2}{*}{$\begin{array}{c}\text { ИМТ } \\
2\end{array}$} & \\
\hline HAD & Абс. & & & & \\
\hline пा & $\%$ & 48,7 & 2,6 & 1,7 & 53 \\
\hline \multirow{2}{*}{ ДМТ } & Абс. & 5 & 16 & 0 & 21 \\
\hline & $\%$ & 4,3 & 13,9 & 0 & 18,3 \\
\hline \multirow{2}{*}{ ИМт } & Абс. & 2 & 0 & 31 & 33 \\
\hline & $\%$ & 1,7 & 0 & 27 & 28,7 \\
\hline \multirow{2}{*}{ Итого } & Абс. & 63 & 19 & 33 & 115 \\
\hline & $\%$ & 54,8 & 16,5 & 28,7 & 100 \\
\hline
\end{tabular}


к изменению массы тела в лагере №2, так же как в лагере № 1 , статистически незначима ( $p=0,585)$.

Тенденция к изменению массы тела в каждой группе по уровню физического развития недостоверна (табл. 4).

При общей тенденции к изменению массы тела в лагере № 3 обнаружено отсутствие изменений у 62 детей с НФР (61,4\%), 13 отдыхающих с ДМТ (12,9\%) и 6 детей с ИМТ (5,9\%). Положительная динамика перехода в течение лагерной смены в группу с НФР отмечена у 6 детей с ДМТ (5,9\%) и 5 отдыхающих с ИМТ (5,0\%). Отрицательная тенденция изменения массы тела к концу лагерной смены выявлена у 9 детей, перешедших из группы с НФР в группу с ДМТ. Среди отдыхающих в лагере № 3 отмечена статистически значимая тенденция к изменению массы тела, $p=0,025$ (табл. 5)

При определении доли детей, у которых наблюдали тенденцию к изменению массы тела в течение смень лагеря № 3, выявили, что случаев с потерей массы тела было статистически значимо больше, чем случаев набора веса $(p=0,025)$. Так, количество отдыхающих, у которых отмечено снижение массы тела, в сумме составило 14 человек (12,2\%), включая 9 детей, перешедших из НФР в ДМТ, и 5 отдыхающих - из ИМТ в НФР. А группу детей с увеличением массы тела составили 6 человек, которые перешли в течение смены из группы с ДМТ в НФР. Следует помнить, что снижение массы тела в течение лагерной смены можно считать признаком положительного оздоровительного эфрфекта только среди детей, у которых в начале смены был отмечен избыток массы тела. И, напротив, для детей с НФР и, тем более, с ДМТ, данные изменения носят отрицательный характер.

Проведен количественный анализ изменения массы тела детей разных групп фризического развития в течение лагерной смены каждой организации отдыха и оздоровления (табл. 6). Показано, что изменения массы тела в группах детей, которые имели НФР и ИМТ к началу лагерной смены, в течение отдыха и оздоровления в каждом лагере статистически недостоверны. Так, в лагере № 1 масса тела детей, относящихся к группе НФР, в начале смены составляла 47,05 $\pm 1,1$ кг, в конце смены 47,34 $\pm 1,12$ кг ( $p=0,347)$. В то же время среди детей, относящихся к группе ДМТ в начале смены, отмечено достоверное увеличение массы тела к моменту окончания периода отдыха. У таких детей в лагере № 2 масса тела в начале смены составляла 39,78 $\pm 1,48$ кг, а в конце смены $41,37 \pm 1,66 \mathrm{~K} \Gamma(p=0,002)$.

Положительную тенденцию к изменению массы тела должны подтверждать соответствующие данные биоимпедансометрии. Безусловно, в течение лагерной смены ребенок должен быть обеспечен полноценным

Таблица 4. Анализ тенденций изменений доли детей с НФР, ИМТ и ДМТ в течение смены лагеря № 2

\begin{tabular}{|c|c|c|c|c|c|c|}
\hline \multirow{2}{*}{ Показатель изменений } & \multicolumn{2}{|c|}{ НФР } & \multicolumn{2}{|c|}{ ДМТ } & \multicolumn{2}{|c|}{ ИМТ } \\
\hline & $n$ & $\%$ & $n$ & $\%$ & $n$ & $\%$ \\
\hline Увеличилось число детей & 8 & 7 & 3 & 2,6 & 2 & 1,7 \\
\hline Уменьшилось число детей & 5 & 4,3 & 6 & 5,2 & 2 & 1,7 \\
\hline Без изменений & 102 & 88,7 & 106 & 92,2 & 111 & 96,5 \\
\hline Итого & 115 & 100 & 115 & 100 & 115 & 100 \\
\hline Статистическая значимость, $p$ & \multicolumn{2}{|c|}{0,581} & \multicolumn{2}{|c|}{0,508} & \multicolumn{2}{|c|}{1} \\
\hline
\end{tabular}

Таблица 5. Анализ изменений уровня физического развития среди детей в лагере № 3

\begin{tabular}{|c|c|c|c|c|c|}
\hline \multirow{2}{*}{\multicolumn{2}{|c|}{ Начало смены }} & \multicolumn{3}{|c|}{ Конец смены } & \multirow{3}{*}{$\begin{array}{c}\text { Итого } \\
71\end{array}$} \\
\hline & & \multirow{2}{*}{$\frac{\mathrm{H} \Phi \mathrm{P}}{62}$} & \multirow{2}{*}{$\frac{\text { ДМТ }}{9}$} & \multirow{2}{*}{$\frac{\text { ИМТ }}{0}$} & \\
\hline HAD & Абс. & & & & \\
\hline 1 & $\%$ & 61,4 & 8,9 & 0 & 70,3 \\
\hline \multirow{2}{*}{ ДМТ } & Абс. & 6 & 13 & 0 & 19 \\
\hline & $\%$ & 5,9 & 12,9 & 0 & 18,8 \\
\hline \multirow{2}{*}{ ИМТ } & Абс. & 5 & 0 & 6 & 11 \\
\hline & $\%$ & 5 & 0 & 5,9 & 10,9 \\
\hline \multirow{2}{*}{ Итого } & Абс. & 73 & 22 & 6 & 101 \\
\hline & $\%$ & 72,3 & 21,8 & 5,9 & 100 \\
\hline
\end{tabular}

Таблица 6. Количественный анализ изменения массы тела детей в течение смены лагерей № 1-3

\begin{tabular}{|c|c|c|c|c|c|c|c|c|c|c|}
\hline \multirow{2}{*}{ Лагерь } & \multirow{2}{*}{$\begin{array}{c}\text { Оценка в начале } \\
\text { смены }\end{array}$} & \multicolumn{3}{|c|}{ Начало смены } & \multicolumn{3}{|c|}{ Конец смены } & \multicolumn{2}{|c|}{ Разница ${ }^{4}$} & \multirow{2}{*}{$p^{6}$} \\
\hline & & $M^{1}$ & $\mathrm{SD}^{2}$ & $m^{3}$ & $M$ & SD & $m$ & $M$ & $\mathrm{SE}^{5}$ & \\
\hline \multirow{3}{*}{ Лагерь № 1} & НФР & 47,05 & 9,03 & 1,1 & 47,34 & 9,16 & 1,12 & 0,29 & 0,3 & 0,347 \\
\hline & ДМТ & 40,49 & 6,64 & 1,28 & 41,56 & 7,72 & 1,49 & 1,07 & 0,4 & 0,014 \\
\hline & ИМТ & 61,92 & 10,3 & 1,72 & 62,59 & 10,5 & 1,75 & 0,67 & 0,55 & 0,228 \\
\hline \multirow{3}{*}{ Лагерь № 2} & НФР & 47,47 & 8,26 & 1,06 & 47,33 & 8,67 & 1,11 & $-0,14$ & 0,29 & 0,627 \\
\hline & ДМТ & 39,78 & 6,77 & 1,48 & 41,37 & 7,63 & 1,66 & 1,6 & 0,46 & 0,002 \\
\hline & ИМТ & 61,16 & 10,18 & 1,77 & 61,51 & 10,83 & 1,89 & 0,35 & 0,46 & 0,458 \\
\hline \multirow{3}{*}{ Лагерь № 3} & НФР & 42,94 & 7,02 & 0,83 & 43,14 & 6,9 & 0,82 & 0,2 & 0,32 & 0,543 \\
\hline & ДМТ & 35,73 & 5,12 & 1,17 & 37,28 & 5,69 & 1,31 & 1,55 & 0,36 & $<0,001$ \\
\hline & ИМТ & 57,66 & 12,21 & 3,68 & 57,07 & 12,85 & 3,87 & $-0,59$ & 0,9 & 0,524 \\
\hline
\end{tabular}


питанием и должным уровнем двигательной активности, что по составу тела будет отражаться в снижении доли жировой массы тела при увеличении скелетномышечной составляющей и удельного обмена. В лагерях № 1 и № 2 выявлены незначительные увеличения средних значений показателей биоимпедансометрии в течение смены, что свидетельствует о должном уровне питания и двигательной активности, однако эти изменения статистически недостоверны. По результатам анализа изменений состава тела детей в течение смены лагеря № 3 отмечено достоверное снижение жировой и скелетномышечной составляющих. Данный факт может быть связан с неадекватным питанием и недостаточным уровнем двигательной активности вследствие неправильной организации режима дня отдыхающих. Данный факт также подтверждают недостоверные изменения уровня удельного обмена у детей лагеря № 3 (табл. 7).

У каждого ребенка в исследованных лагерях был проведен анализ изменений ЖМ, СММ и УО. Выделено семь групп изменений биоимпедансометрических показателей (табл. 8). Группа изменения показателей БИА № 1 и № 3 свидетельствует о достаточном уровне двигательной активности и полноценном питании отдыхающих. Среди детей, которые по результатам анализа изменений БИА вошли в группу № 2, отмечены нормальный уровень двигательной активности и недостаточное в количественном отношении питание. Изменения БИА № 4 свидетельствуют об избыточном энергопотреблении, поступающем с пищей, в сравнении с энергозатратами, необходимыми при достаточном уровне двигательной активности. В свою очередь среди детей, которые по результатам анализа изменений БИА вошли в группы № 5, 6 и 7, отмечен недостаточный уровень двигательной активности при одновременно избыточном рационе питания (табл. 8).
Наибольшая доля детей, имеющих положительную тенденцию изменения состава тела (группы 1-3) в течение смены, выявлена в лагерях № 1 и № $2-44,61 \%$ и 44,34\% соответственно. При этом, как в первой, так и во второй организации отдыха и оздоровления отмечено большое количество отдыхающих, у которых обнаружены негативные изменения показателей БИА: повышение жировой массы при снижении или отсутствии изменений скелетно-мышечной составляющей. В лагере № 3 изменения показателей БИА среди большинства детей (19,8\%) характеризовались повышением ЖМ, а также понижением показателей СММ и УО, что подтверждает результаты анализа антропометрических изменений. Помимо этого, весомая доля детей в группах изменений БИА № 1-3 подтверждает общую тенденцию к изменению массы тела в лагере № 3 .

\section{ОБСУЖДЕНИЕ РЕЗУЛЬТАТОВ}

В результате антропометрических исследований выявлены дети, у которых за время лагерной смены отмечается негативная (отрицательная) тенденция изменения массы тела, которая проявлялась переходом детей из группь с нормальным физическим развитием в начале смены в группу с ДМТ или ИМТ в конце отдыха. Тревожным является тот факт, что подобные изменения обнаружены в каждом из обследованных лагерей. В лагере № 3 отмечена статистически значимая общая тенденция к изменению массы тела, которая связана не только с так называемым положительным эффектом оздоровления, проявляющимся в повышении массы тела среди детей с нормальным физическим развитием и среди детей с дефицитом массы, но и с отсутствием оздоровительного эффекта, выражающимся в выявленной высокой доле детей с потерей массы тела в течение смены. Проведенная

Таблица 7. Анализ показателей состава тела детей в течение смены лагерей № 1-3

\begin{tabular}{|c|c|c|c|c|c|c|c|c|}
\hline \multirow{2}{*}{ Лагерь } & \multirow{2}{*}{ Показатель БИА } & \multicolumn{2}{|c|}{ Начало смены } & \multicolumn{2}{|c|}{ Конец смены } & \multicolumn{2}{|c|}{ Разница ${ }^{4}$} & \multirow{2}{*}{$p^{6}$} \\
\hline & & $\mathrm{M}^{1} \pm m^{2}$ & $\mathrm{P}_{25-75^{3}}$ & $\mathrm{M} \pm m$ & $\mathrm{P}_{25-75}$ & M & $\mathrm{SE}^{5}$ & \\
\hline \multirow{3}{*}{ Лагерь № 1} & ЖM (кг) & $10,89 \pm 0,44$ & $7,7-13,9$ & $11,29 \pm 0,49$ & $7,3-14,3$ & 0,4 & 0,29 & 0,473 \\
\hline & CMM (кг) & $21,23 \pm 0,46$ & $17,5-25,1$ & $21,35 \pm 0,45$ & $18-25,1$ & 0,12 & 0,4 & 0,687 \\
\hline & Удельный обмен (ккал/кв.м) & $857,04 \pm 4,98$ & $824-888$ & $865,27 \pm 5,38$ & $835-894$ & 8,23 & 0,65 & 0,262 \\
\hline \multirow{3}{*}{ Лагерь № 2} & ЖM (кг) & $12,32 \pm 0,56$ & $8,1-16,5$ & $13,09 \pm 0,38$ & $8,3-17,9$ & 0,77 & 0,35 & 0,198 \\
\hline & CMM (кг) & $20,45 \pm 0,34$ & $16,6-24,3$ & $20,84 \pm 0,56$ & $17.2-24.5$ & 0,39 & 0,46 & 0,478 \\
\hline & Удельный обмен (ккал/кв.м) & $832,54 \pm 5,34$ & $798-867$ & $846,01 \pm 4,78$ & $813-879$ & 13,47 & 0,58 & 0,061 \\
\hline \multirow{3}{*}{ Лагерь № 3} & ЖM (кг) & $12,35 \pm 0,55$ & $8,7-15,9$ & $10,89 \pm 0,44$ & $7,3-14,3$ & $-1,46$ & 0,46 & 0,039 \\
\hline & CMM (кг) & $23,43 \pm 0,57$ & $19,3-27,5$ & $21,81 \pm 0,55$ & $18,5-25,3$ & $-1,62$ & 0,42 & 0,041 \\
\hline & Удельный обмен (ккал/кв.м) & $873,32 \pm 5,45$ & $849-897$ & $862,51 \pm 5,29$ & $836-889$ & $-10,81$ & 0,51 & 0,155 \\
\hline
\end{tabular}

Таблица 8. Анализ изменения показателей состава тела детей в организациях отдыха и оздоровления

\begin{tabular}{|c|c|c|c|c|}
\hline \multirow{2}{*}{ Группа } & \multirow{2}{*}{ Изменения показателей } & \multicolumn{3}{|c|}{ Количество детей (\%) } \\
\hline & & Лагерь № 1 & Лагерь № 2 & Лагерь № 3 \\
\hline 1 & Понижение ЖМ, неизменная СММ, повышение УО & $17(13,07)$ & $14(12,17)$ & $12(11,89)$ \\
\hline 2 & Понижение ЖМ, повышение СММ, понижение УО & $12(9,23)$ & $16(13,91)$ & $11(10,89)$ \\
\hline 3 & Понижение ЖМ, повышение СММ, повышение УО & $29(22,31)$ & $21(18,26)$ & $17(16,83)$ \\
\hline 4 & Повышение ЖМ, СММ, УО & $14(10,77)$ & $14(12,17)$ & $13(12,87)$ \\
\hline 5 & Повышение ЖМ, неизменная СММ, понижение УО & $20(15,39)$ & $17(14,79)$ & $19(18,81)$ \\
\hline 6 & Повышение ЖМ, понижение СММ, понижение УО & $24(18,46)$ & $14(12,17)$ & $20(19,8)$ \\
\hline 7 & Повышение ЖМ, понижение СММ, повышение УО & $14(10,77)$ & $19(16,53)$ & $9(8,91)$ \\
\hline
\end{tabular}


в каждой организации отдыха и оздоровления биоимпедансометрия подтверждает и раскрывает результаты антропометрических исследований. По результатам анализа изменения жировой, скелетномышечной составляющих и уровня обмена в течение лагерной смены у каждого отдыхающего ребенка мы можем делать выводы об эффективности оздоровления в части изменения пищевого статуса. Ведь повышение массы тела, регламентированное в нормативно-методических документах как один из критериев оздоровительного эффекта, может быть связано с повышением жировой составляющей $[17,20,25]$. В случае организации полноценного питания, должного уровня двигательной активности и достигаемого при этом соответствия уровня энергопотребления уровню энергозатрат в детском лагере, изменения состава тела отдыхающих детей не будут проявляться повышением жировой массы. А уровень скелетно-мышечной составляющей к концу лагерной смены может как увеличиваться, так и оставаться в пределах значений, характерных для начала отдыха $[18,19,25]$. В результате оценки состава тела детей в изученных лагерях показано, что повышение массы тела в течение лагерной смены сопровождалось как должным повышением скелетно-мышечной составляющей, так и в высокой доле случаев повышением жировой массы. В то же время снижение массы тела детей в течение лагерной смены включало как должную потерю жировой составляющей, так и снижение доли скелетно-мышечной массы, что указывает на отсутствие оздоровительного эффекта. Результаты антропометрических и биоимпедансометрических изменений в лагере № 1 позволяют предположить, что питание в лагере было полноценным и соответствовало в большинстве случаев уровню двигательной активности отдыхающих детей. По результатам исследований в лагере № 2 можно предположить об избыточном поступлении пищевых веществ или же о повышенном энергопотреблении в сравнении с энергозатратами среди большей доли отдыхающих детей. В то же время выявленные изменения среди детей в лагере № 3 дают нам возможность говорить о недостаточном питании отдыхающих или о сниженной энергетической ценности рациона в сравнении с энергозатратами в данном лагере.

\section{ВЫВОДЫ}

Организм ребенка в течение лагерной смены реагирует на условия пребывания в организации отдыха и оздоровления, что проявляется изменениями не только антропометрических признаков, но и показателей состава тела, характеризующих в том числе фактический пищевой статус. Результаты анализа динамики антропометрических данных и изменений показателей биоимпедансного анализа состава тела детей позволяют сделать предположения о фактически получаемом питании и уровне двигательной активности в исследуемых лагерях. Таким образом, применение антропометрических исследований в совокупности с данными биоимпедансного анализа может служить информативной методикой для оценки адекватности питания детей в персонализированном подходе, оценки двигательной активности и, как следствие, в качестве критериев оценки эффективности оздоровления детей в летних организациях отдыха и оздоровления.

\section{Литература}

1. Баранов А. А., Кучма В. Р., Скоблина Н. А., Милушкина О. Ю., Бокарева Н. А., Ямпольская Ю. А. Физическое развитие детей и подростков Российской Федерации. М., 2013. 192 с.

2. Скоблина Н. А., Федотов Д. М., Милушкина О. Ю., Бокарева Н. А., Татаринчик А. А. Характеристика физического развития детей и подростков Архангельска и Москвы: исторические аспекты. Вестник Северного (Арктического) федерального университета. 2016; (2): 110-22.

3. Баранов А. А., Кучма В. Р., Скоблина Н. А., Милушкина О. Ю., Бокарева Н. А. Основные закономерности морфофункционального развития детей и подростков в современных условиях. Вестник Российской академии медицинских наук. 2012; (12): 35-40.

4. Кучма, В. Р. Межсекторальное взаимодействие при формировании здорового образа жизни детей и подростков: проблемы и пути решения. Вопросы школьной и университетской медицины и здоровья. 2014; (3): 4-9.

5. Зигитбаев Р. Н., Ахмадуллина Г. Х., Поварго Е. А., Зулькарнаев Т. Р. Сравнительная оценка состояния здоровья школьников в условиях промышленных городов республики Башкортостан. Медицинский вестник Башкортостана. 2017; 12 (5): 15-20.

6. Грицинская В. Л. Характеристика физического развития и питания школьников городского и сельского населения Красноярского края. Вопросы детской диетологии. 2012; (5): 8-11.

7. Мальцева Е. А., Чеснокова Л. Л., Михайлова Л. А. Антропометрические показатели детей препубертатного возраста промышленного города. Современные проблемы науки и образования. 2016; (6): 22.

8. Скоблина Н. А., Милушкина О. Ю., Гудинова Ж. В., Бокарева Н. А., Гаврюшин М. Ю., Сазонова О. В. и др. Научно-методическое обоснование границ нормы массы тела, используемых при разработке нормативов физического развития детского населения. Здоровье населения и среда обитания. 2018; 9 (306): 19-22.

9. ВОЗ. Ожирение и избыточный вес. Десятикратный рост числа детей и подростков с ожирением за последние сорок лет: новое исследование Имперского колледжа в Лондоне и ВОЗ. Доступно по ссылке: http://www.who.int/mediacentre/ news/releases/2017/increase-childhood-obesity/ru/ (дата обращения: 22.12.2018).

10. Батурин А. К., Погожева А. В., Мартинчик А. Н., Сафрронова А. М., Кешабянц Э. Э., Денисова Н. Н., Кобелькова И. В. Изучение особенностей питания населения Европейской и Азиатской части арктической зоны России. Вопросы питания. 2016; 85 (2): 83.

11. Котельников Г. П., Крюков Н. Н., Гридасов Г. Н., Батурин А. К., Гильмиярова Ф. Н., Березин И. И. и др. Обоснование программы реализации основ государственной политики здорового питания населения Самарской области на период до 2020 года. Вопросы питания. 2011; (2): 52-7.

12. Тапешкина Н. В., Клишина М. Н. Организация школьного питания в современных условиях: проблемы и пути решения. Сибирский медицинский журнал (Иркутск). 2013; 122 (7): 113-7.

13. Конь И. Я., Тутельян В. А., Углицкий А. К., Волкова Л. Ю. Рациональное питание российских школьников: проблемы и их пути преодоления. Здоровье населения и среда обитания. 2008; 7 (184): 4-5.

14. Горелова Ж. Ю., Кучма В. Р., Соловьева Ю. В., Летучая Т. А., Плац-Колдобенко А. Н., Углов С. Ю. Научное обоснование и разработка вариантов школьного меню (12 дневных суточных рационов) с учетом домашнего питания. Основные принципы, особенности и преимущества. Евразийское Научное Объединение. 2017; 3 (25): 71-7. 
15. Самарский статистический ежегодник: Стат. сборник. Самара: Самарастат, 2016. 345 с.

16. Седова А. С., Соколова С. Б., Лапонова Е. Д. Динамика функционального состояния организма детей в условиях укороченной смены стационарной организации отдыха Вопросы школьной и университетской медицины и здоровья. 2016; (4): 41-7.

17. Методические рекомендации МР 2.4.4.0127-18 «Методика оценки эффективности оздоровления в стационарных организациях отдыха и оздоровления детей». Утверждень Главным государственным санитарным врачом РФ 11 мая 2018 г. Доступно по ссылке: https://www.garant.ru/products/ ipo/prime/doc/71875014/.

18. Танина Н. А. Оценка эффективности оздоровительных мероприятий в летних загородных учреждениях отдыха и оздоровления детей. Медицинский альманах. 2015; 2 (37): 77-9.

19. Платонова А. Г., Подригало Л. В. Использование двигательной активности для оценки эффективности оздоровления детей Вопросы школьной и университетской медицины и здоровья. 2014; (3): 51-2.

20. Новикова И. И., Вейних П. А. Методические аспекть оценки эффективности оздоровления детей и подростков в современных условиях. Вести МАНЭБ в Омской области. 2013; 3 (3): 30-3.
21. Блинова Е. Г., Акимова И. С., Чеснокова М. Г., Демакова Л. В. Результаты анализа антропометрических и биоимпедансометрических исследований у студентов города Омска. Современные проблемы науки и образования. 2014; (3): 543.

22. Mok E, Letellier G, Cuisset JM, et al., Assessing change in body composition in children with Duchenne muscular dystrophy: anthropometry and bioelectrical impedance analysis versus dualenergy X-ray absorptiometry. Clin Nutr. 2010; 29 (5): 633-8.

23. Кучма В. Р., Вишневецкая Т. Ю., Ямщикова Н. Л. Исследование физического развития детей и подростков В системе социально-гигиенического мониторинга. Методические указания. Утверждены заместителем главного государственного санитарного врача г. Москвы 12.07.99 г. М., 1999. 37 C.

24. Вдовенко С. А., Сазонова О. В., Пономарев В. А., Мазур Л. И., Гаврюшин М. Ю., Бородина Л. М. Оценочные таблицы физического развития детей и подростков школьного возраста Самарской области. Методические рекомендации. Самара, 2018. 46 c.

25. Николаев Д. В., Щелыкалина С. П. Лекции по биоимпедансному анализу состава тела человека. М., 2016. 152 с.

26. Руднев С. Г., Соболева Н. П., Стерликов С. А., Николаев Д. В., Старунова О. А., Черных С. П. и др. Биоимпедансное исследование состава тела населения России. М., 2014. 493 с.

\section{References}

1. Baranov AA, Kuchma VR, Skoblina NA, Milushkina OYu, Bokareva NA, Yampolskaya YuA. Physical development of children and adolescents of the Russian Federation. M., 2013. 192 p.

2. Skoblina NA, Fedotov DM, Milushkina OYu, Bokareva NA, Tatarinchik AA. Characteristics of physical development of children and adolescents in Arkhangelsk and Moscow: history aspects. Vestnik Severnogo (Arkticheskogo) federal'nogo universiteta. 2016. (2): 110-22.

3. Baranov AA, Kuchma VR, Skoblina NA, Milushkina OYu, Bokareva NA. The main mechanisms of morphofunctional development of children and adolescents in modern conditions. Vestnik Rossijskoj akademii medicinskih nauk. 2012; (12): 35-40.

4. Kuchma VR. Inter-sectoral collaboration in the formation of a healthy lifestyle of children and teenagers: problems and solutions. Voprosy shkol'noj i universitetskoj mediciny i zdorov'ya. 2014; (3): 4-9.

5. Zigitbaev RN, Ahmadullina GH, Povargo EA, Zulkarnaev TR. Sravnitel'naya ocenka sostoyaniya zdorov'ya shkol'nikov v usloviyah promyshlennyh gorodov respubliki Bashkortostan. Medicinskij vestnik Bashkortostana. 2017; 12 (5): 15-20.

6. Gricinskaja VL. Characteristics of physical development and nutrition of schoolchildren of urban and rural population of Krasnoyarsk region. Pediatric Nutrition. 2012; (5): 8-11.

7. Malceva EA, Chesnokova LL, Mihajlova LA. Anthropometrical indicators of children of prepubertatny age of the industrial city. Sovremennye problemy nauki i obrazovanija. 2016; (6): 22.

8. Skoblina NA, Milushkina OYu, Gudinova ZhV, Bokareva NA, Gavryushin MYu, Sazonova O.V., et al. The scientific-methodical substantiation of norms of body weight and the standards for physical development of children's population. Zdorov'e naseleniya i sreda obitaniya. 2018; 9 (306): 19-22.

9. Tenfold increase in childhood and adolescent obesity in four decades: new study by Imperial College London and WHO. Available from: http://www.who.int/mediacentre/news/releases/ 2017/increase-childhood-obesity/ru/ (Data obrashcheniya: 22.12.2018)

10. Baturin AK, Pogozheva AV, Martinchik AN, Safronova AM, Keshbyants EE, Denisova NN, et al. Study of nutrition peculiarities of the population of the European and Asian part of the Arctic zone of Russia. Problems of nutrition. 2016; 85 (2): 83.

11. Kotelnikov GP, Krjukov NN, Gridasov GN, Baturin AK, Gilmiyarova FN, Berezin II, et al. The rationale for the implementation of the

principles of state policy of healthy nutrition of the population of Samara region for the period till 2020. Problems of nutrition. 2011; (2): 52-7.

12. Tapeshkina NV, Klishina MN. The organization of school in the modern conditions: problems and solutions. Sibirskij meditsinskij zhurnal (Irkutsk). 2013. 122 (7): 113-7.

13. Kon IYa, Tutelyan VA, Uglickij AK, Volkova LYu. Racional'noe pitanie rossijskih shkol'nikov: problemy $\mathrm{i}$ in puti preodoleniya. Zdorov'e naseleniya i sreda obitaniya. 2008; 7 (184): 4-5

14. Gorelova ZhYu, Kuchma VR, Solovyeva YuV, Letuchaya TA, PlatsKoldobenko AN, Uglov SYu. Scientific substantiation and working out of a school menu options (12 day daily rations), taking into account domestic supply. The basic principles, features and benefits. Evrazijskoe Nauchnoe Ob"edinenie. 2017; 3 (25): 71-7.

15. Samarskij statisticheskij ezhegodnik: Stat. sbornik. Samara: Samarastat, 2016. $345 \mathrm{~s}$

16. Sedova AS, Sokolova SB, Laponova ED. Dynamics of functional state of children's body in conditions of shortened shifts of stationary recreation. Voprosy shkol'noj i universitetskoj mediciny i zdorov'ya. 2016; (4): 41-7.

17. Metodicheskie rekomendacii MR 2.4.4.0127-18 «Metodika ocenki ehffektivnosti ozdorovleniya $v$ stacionarnyh organizaciyah otdyha i ozdorovleniya detej». Utverzhdeny Glavnym gosudarstvennym sanitarnym vrachom RF 11 maya 2018 g. Available from: https:// www.garant.ru/products/ipo/prime/doc/71875014/.

18. Tanina NA. Evaluation of healthcare measures efficiency in summer out-of-town recreational and rehabilitation facilities for children. Medicinskij al'manah. 2015; 2 (37): 77-9.

19. Platonova AG, Podrigalo LV. Application of motor activity for the evaluation of the effectiveness of children's rehabilitation. Voprosy shkol'noj i universitetskoj mediciny i zdorov'ya. 2014; (3): 51-2.

20. Novikova II, Vejnih PA. Metodicheskie aspekty ocenki ehffektivnosti ozdorovleniya detej i podrostkov $v$ sovremennyh usloviyah. Vesti MANEB v Omskoj oblasti. 2013; 3 (3): 30-3

21. Blinova EG, Akimova IS, Chesnokova MG, Demakova LV. The results of the analysis of the anthropometric and bioimpendancemetria studies of students of Omsk city. Sovremennye problemy nauki i obrazovanija. 2014; (3): 543 p.

22. Mok E, Letellier G, Cuisset JM, et al. Assessing change in body composition in children with Duchenne muscular dystrophy: anthropometry and bioelectrical impedance analysis versus dualenergy X-ray absorptiometry. Clin Nutr. 2010; 29 (5): 633-8. 


\section{ORIGINAL RESEARCH I HYGIENE}

23. Kuchma VR, Vishneveckaya TYu, Yamshchikova NL. Issledovanie fizicheskogo razvitiya detej i podrostkov $v$ sisteme social'nogigienicheskogo monitoringa. Metodicheskie ukazaniya. Utverzhdeny zamestitelem glavnogo gosudarstvennogo sanitarnogo vracha g. Moskvy 12.07.99 g. M., 1999. 37 p.

24. Vdovenko SA, Sazonova OV, Ponomarev VA, Mazur LI, Gavryushin MYu, Borodina LM. Ocenochnye tablicy fizicheskogo razvitiya detej i podrostkov shkol'nogo vozrasta Samarskoj oblasti. Metodicheskie rekomendacii. Samara, 2018. 46 p.

25. Nikolaev DV, Shchelykalina SP. Bioimpedance analysis of the human body composition: Lectures. M., 2016. 152 p.

26. Rudnev SG, Soboleva NP, Sterlikov SA, Nikolaev DV, Starunova OA, Chernykh SP, et al. Bioimpedance study of body composition in the Russian population. M., 2014. 493 p. 